\title{
The Spatial-temporal Statistical Analysis of Lightning Behavior over Hainan Island
}

\author{
Wensheng Gao, Ruixu Zhou \\ Department of Electrical Engineering, Tsinghua University, \\ Beijing, China \\ wsgao@mail.tsinghua.edu.cn
}

\author{
Bowen Zhang \\ China Electrical Power Research Institute, Beijing, China \\ zhangbowen@epri.sgcc.com.cn
}

\author{
Xianggan Fu, Qinzhu Chen, Song Huang, Yafeng Liang \\ Hainan Power Grid Corporation, Haikou, Hainan \\ chenqz@foxmail.com
}

\begin{abstract}
By study on lightning data in 2010 2013 from lightning location system of Hainan Power Grid Corporation, the spatial-temporal distribution of flashes on Hainan island were achieved. The results showed that Hainan thunderstorm activity was very frequent, where a high number of lightning occurred from May to September; there is a strong correlation between the lightning intensity of Hainan island and NINO3.4 index; the temporal distribution of Lightning on Hainan island has obvious "twin peaks" characteristics, as well as daily flashes; the large flash density of Hainan island mainly appeared in the mountainous areas in the northeast, and most centered on windward area.
\end{abstract}

\section{Keywords-power grid; lightning; parameters}

\section{INTRODUCTION}

Thunderstorm is local convection caused by strong cumulonimbus accompanied by thunder and lightning activity, and it also means a weather phenomenon accompanied by thunder and lightning in ground observation. Thunderstorm is one of the major natural meteorological disaster weather, directly threatening people's life and property security. Hainan island, a high incidence zone of thunderstorms, where local strong convective weather is very frequent, is located in the subtropical area, affected by both tropical system activity and the cold air from time to time. thunderstorm days of most of the cities and counties(Huang Yanbin et al.) in Hainan island is above 100, after typhoon, lightning damage is the second major meteorological disasters in Hainan island. from different angles, various researches of thunderstorm in Hainan area by statistical analysis approaches has been made, such as atmospheric circulation background(dong-yan guo) and convective parameters of thunderstorms in Hainan area, and thunderstorms features (Xin Jiwu et al) in Danzhou area of Hainan island. In this paper, statistical analysis of the spatial and temporal distribution of cloud-to-ground(CG) lightning in Hainan area was carried out, aiming to provid beneficial references for differential lightning protection design of transmission lines in the region, on the basis of the the spatial-temporal distribution and the performance diversification of CG flash study in Hainan island ${ }^{[1-9]}$.

\section{APPROACHES}

Hainan island is a tropical monsoon climate, with strong lightning activity, and it is the country's most serious lightning hotspot and one of the hardest-hit area. Lightning Location System of Hainan island (LLSH) was completed and put into operation in February 2005 with seven lightning detection stations, including East, Tunchang, mannings, qinlan, Wengtian, Sanya and Wuzhishan, forming a good cover of Hainan province. LLSH can provide real-time measurement of lightning time, location and the parameters such as amplitude, polarity, number of return stroke, accumulating a number of basic data for transmission line lightning forecasting researches.

LLSH is a set of automatic, high precision, real-time lightning monitoring system, covering large area, with the abilities of real-time telemetry and display of time, location, current peak and polarity, number parameters of each return stroke of the CG flash. The composition block diagram of the LLSH was shown in Figure 1, consisting of three parts:

\section{A. Detection Station}

It is deployed for direct detection of lightning parameters, two and above stations laid out in different geographical position station make a lightning detection network;

\section{B. Control Center}

The central station consists of three parts: the frontend processor, position analyzer and Web application server. Frontend is responsible for receiving data from detecting station, showing detection station working status and detection results, position analyzer mainly collects and keeps various lightning information from detecting station, and makes position analysis calculation, Web application server can store the results and provide Web service for network users.

\section{User Workstation}

The user workstation can display real-time lightning location data and provide historical data query of the CG lightning. 


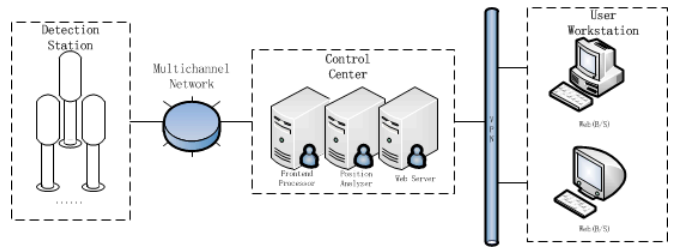

Figure 1. Composition block diagram of LLSH.

Lightning is a discharge phenomenon of the atmosphere with large current, high voltage and strong radiation, CG lightning location is mainly related to the distribution of positive and negative charge on the clouds, distribution of electric field near the ground and insulation strength of air, etc, and the real-time change of these factors also results in the characteristics of dispersibility and randomness of lightning, hence from the perspective of lightning protection, a detailed statistical analysis of lightning parameters and digging the common features of regional lightning activities of a particular area, will help the power grid corporations make different operation maintenance plan in accordance with the requirements of transmission line insulation level and corresponding lightning activity characteristics of the same region, improving the efficiency of line patrol and personnel utilization, and operational management level, providing reference for modification works of the transmission lines and substations.

This article mainly discussed time characteristics and trends of lightning activity, from the perspective of statistics according to four kinds of different granularity of time, including month, quarter, year, and hour, by the approach of raster analysis, the distribution regularity of CG lightning of Hainan island was studied. Based on metrical data from 2010 to 2013 from LLSH, a deep statistical analysis was made, due to the poor authenticity, information obtained by detecting locations less than three was omitted in order to guarantee the accuracy of the results.

\section{TEMPORAL FEATURES}

The purpose of this paper is to demonstrate a detailed distribution of lightning events of Hainan island respectively from year, quarter, month and hour, to reveal statistical characteristics and change rules lightning frequency on all kinds of time scale of Hainan island ${ }^{[10-11]}$.

\section{A. Yearly Distribution}

In the statistical results of CG lightning number in Hainan island from 2010 to 2013 was displayed in TAB.1, during that time, the sum of CG flashes of Hainan area is about 1.75 million times, an average of 0.44 million times in one year, and 2010 accounted for the largest proportion at $44.67 \%$, the rest share an average of around $20 \%$ in one year, with the deviation less than 5\%, CG flash number and proportion from 2010 to 2013 in Hainan island were displayed in Figure 2.

We can see that, Hainan island CG lightning quantity of each year among 2011 and 2013 was very close, however, in 2010, the total number of CG lightning climbed to about 2 times comparing to the average quantity from 2011 to
2013. Generally, CG lightning number depends on the number of thunderstorm cell and the lightning rate of thunderstorm monomer, in normal conditions, the annual average lightning rate of thunderstorm monomer in the same regional will not fluctuate strongly, so presumably the cause resulting in the surge of CG lightning quantity in 2010, is the rapid increase of the thunderstorm cell number. In another hand, lightning was positively correlated with precipitation, therefor it can partly be reflected by rainfall, according to meteorological data, the annual rainfall of Hainan island in 2010 is approximately $2251.8 \mathrm{~mm}, 28.7 \%$ more than an average level, and the annual rainfall concentrated in summer and autumn, during 1th and 18th in October that year, the average rainfall reached up to 1040.6 $\mathrm{mm}$, five times more than in the same period of former years $(181.4 \mathrm{~mm})$, and $46 \%$ of the total precipitation that year.

TABLE I. C C Flahes OF HAINAN ISLAND From 2010 To 2013

\begin{tabular}{|l|c|c|c|c|}
\hline \multicolumn{1}{|c|}{ Year } & 2010 & 2011 & 2012 & 2013 \\
\hline $\begin{array}{l}\text { Lightning } \\
\text { Quantity }\end{array}$ & 782152 & 355764 & 287607 & 325396 \\
\hline Proportion & $44.67 \%$ & $20.31 \%$ & $16.44 \%$ & $18.58 \%$ \\
\hline
\end{tabular}

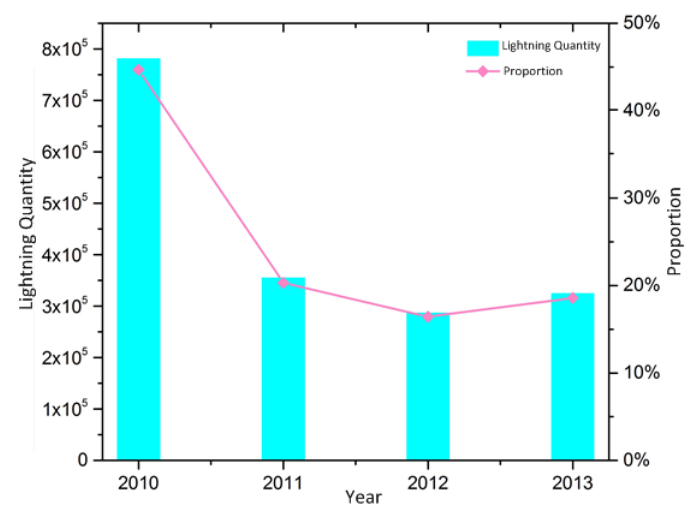

Figure 2. CG lightning quantity and proportion of Hainan island from 2010 to 2013.

Comparing to circulation data, in early October, 2010, the western Pacific subtropical high power is quite stronger, driven by the strong easterly flow in the upper air, a large number of air above sea containing rich moisture continued to be blown from east to west to Hainan island. Because the relatively higher terrain of central Hainan island, the eastern airflow entering the island climbed along the terrain, resulting in the heavy rain in the island, especially the eastern windward areas.

El Nino and La Nina is respectively refers to the abnormal warmer and colder phenomenon of the surface temperature of the eastern and central equatorial Pacific ocean, and the cycle constituted by regular temperature change process, can cause significant influence to the world especially the Pacific climate. During la Nina years, the water of the equatorial eastern Pacific Ocean unusually rises to the surface strongly, with fewer precipitation, the reverse is also true on the equatorial western Pacific Ocean. While 
in El Nino years, vice versa. NINO3.4 index is an reflect to the degree of temperature abnormality in the Pacific Ocean, the positive value represents an higher ocean temperature than average level, while the negative stand for the lower, Figure 3 shows the variation of NINO3.4 index from 2010 to 2010. By the graph, you can see that from April, 2010, NINO3.4 index continued to be below zero, when la Nina phenomenon appears, and from May to October rich in thunderstorm, the index was less than 1.0, indicating that from May to October in 2010, the trade winds of the western Pacific Ocean is strong, precipitation will be much more than the average level, in the meantime, Hainan island is located in the west of the Pacific Ocean, near the equator, and belongs to the tropical monsoon climate, therefore, the cause of extreme precipitation in Hainan island in 2010 is exactly the la Nina event.

After carefully scrutinize to the lightning quantity change of Hainan island and the negative value of NINO3.4 index during $2010 \sim 2013$ ground, it can be found that both the trends are moving close to the horizontal axis, which verifies further the la Nina effection on precipitation of Hainan island, in order to study relationship between NINO3.4 index and the number of CG lightning of Hainan island, the exponential sum of NINO3.4 index among May and October from 2010 to 2013 are calculated respectively, to prevent the negative distortion, take the arithmetic sum as the power exponent (a), matched by different bases (x), followed by the normalization, the result is shown in Figure 4 and Table 2. The cause of choosing only months from May to October is to eliminate the effection of other months of much less CG flash ${ }^{[12]}$.

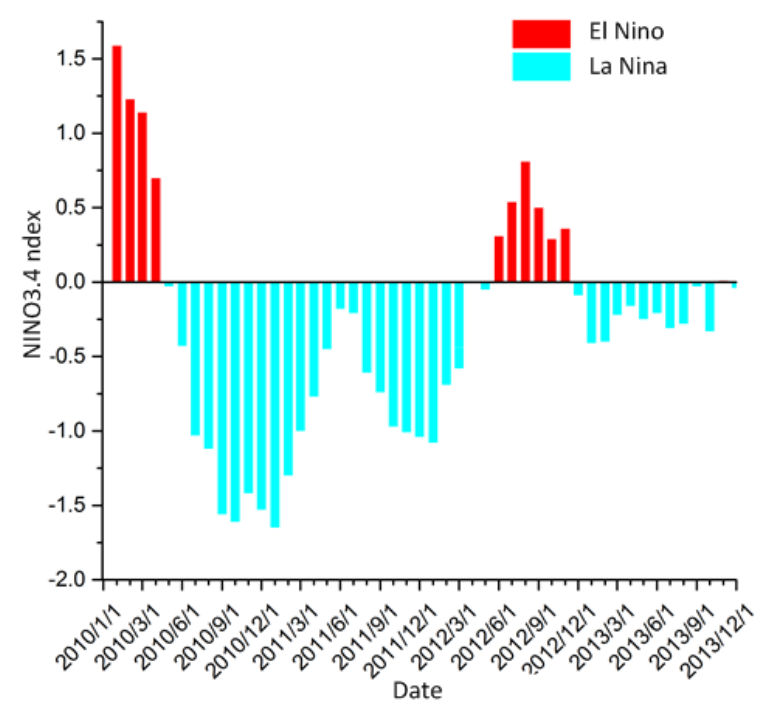

Figure 3. NINO3.4 Index of each month from 2010 to 2013

Figure 4 gives values of different base taken NINO3.4 index as power exponent, and also the correlation analysis of the curves fitting curves of different base and CG lightning proportion, the results were displayed in Table 3. As we can see, when taking 2.0, 2.5, e as the base, the statistical significance is less than 0.05 , with relevant coefficients greater than 0.9 , indicating that a strong correlation, comparing all three kinds of fitting curve, obviously when taking e as the base, the fitting curve is optimal, therefore, we can get equation (1):

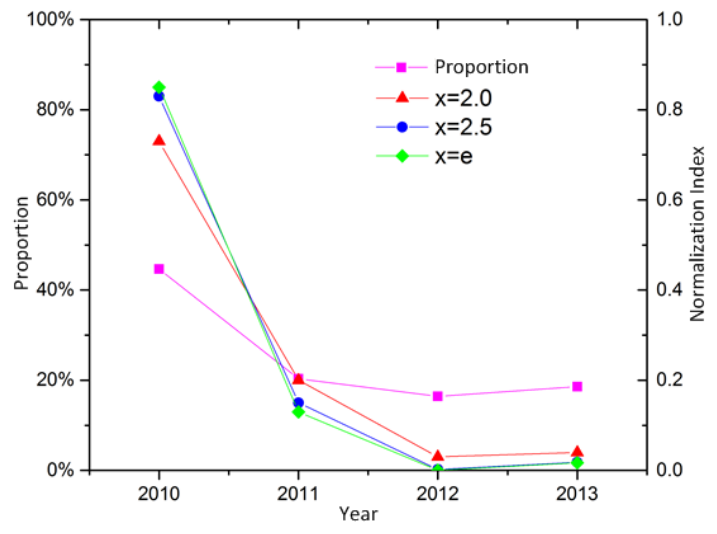

Figure 4. Fitting curve of power function with NINO3.4 as index and 2.0,2.5,e as base

TABLE II. POWER FUnCTION VALUE With NinO3.4 As INDEX AND 2.0,2.5,E AS BASE

\begin{tabular}{|c|c|c|c|c|c|}
\hline \multicolumn{2}{|c|}{ Year } & 2010 & 2011 & 2012 & 2013 \\
\hline \multicolumn{2}{|c|}{ Index(a) } & 5.78 & 3.93 & -1.96 & 1.57 \\
\hline \multirow{6}{*}{ Base } & 2.0 & 54.95 & 15.24 & 2.57 & 2.97 \\
\hline & Norm & 0.73 & 0.20 & 0.03 & 0.04 \\
\hline & 2.5 & 199.57 & 36.64 & 0.17 & 4.21 \\
\hline & Norm & 0.83 & 0.15 & 0.002 & 0.018 \\
\hline & $\mathrm{E}$ & 323.76 & 50.91 & 0.14 & 4.81 \\
\hline & Norm & 0.85 & 0.13 & 0.0003 & 0.017 \\
\hline
\end{tabular}

TABLE III. CORRELATION COEFFICIENT AND SigNIFICANCE WITH DIFFERENT BASE

\begin{tabular}{|c|c|c|c|}
\hline Index & $\mathbf{2 . 0}$ & $\mathbf{2 . 5}$ & $\boldsymbol{e}$ \\
\hline $\begin{array}{l}\text { Correlation } \\
\text { Coefficient }\end{array}$ & 0.9891 & 0.9964 & 0.9979 \\
\hline Significance & 0.0109 & 0.0036 & 0.0021 \\
\hline
\end{tabular}

$$
y=e^{a}
$$

Latest research can accurately forecast the occurrence of EL Nino in advance of 6 months to 1 year, therefore, by equation (1), we can estimate the CG lightning quantity of Hainan island in the next year 6 months to 1 year ahead, to adopt targeted measures for lightning protection, to ensure a safe and stable operation of the power grid.

\section{B. Monthly Distribution}

CG lightning numbers of each month of Hainan island among 2010 and 2013 were displayed in Table 4 and Figure 5, and Figure 6 demonstrate CG lightning number of each months on average of the four years. 
From CG lightning number distribution of each month, lightning events in Hainan island are mainly concentrated from May to October, while May, June, August and September take the largest proportion, accounting for $70 \%$ of the total amount. In Summer, the lightning activity is the strongest, with about 0.21 million times CG flashes on average during 2010 and 2013, accounting for about 47.8\% of the whole year, the second is the spring and autumn, with total numbers of $28.8 \%$ and $22.9 \%$ respectively, In winter, lightning activity is weak, which is consistent with the practical experience. From flashes in four years distribution on average, lightning events in September is the strongest, of a total of 82000 times, covering $18.7 \%$ of the whole year $^{[13]}$.

TABLE IV. MONTHLy Cg Flashes QUANTITY From 2010 To 2013

\begin{tabular}{|c|c|c|c|c|}
\hline \multirow{2}{*}{ Month } & \multicolumn{4}{|c|}{ CG Flashes Quantity } \\
\cline { 2 - 5 } & $\mathbf{2 0 1 0}$ & $\mathbf{2 0 1 1}$ & $\mathbf{2 0 1 2}$ & $\mathbf{2 0 1 3}$ \\
\hline 1 & 1252 & 632 & 162 & 47 \\
\hline 2 & 3183 & 507 & 176 & 45 \\
\hline 3 & 1126 & 1322 & 363 & 34684 \\
\hline 4 & 25744 & 41154 & 74561 & 27557 \\
\hline 5 & 87538 & 72183 & 42825 & 94811 \\
\hline 6 & 142753 & 79641 & 25775 & 43400 \\
\hline 7 & 107831 & 41225 & 52363 & 45766 \\
\hline 8 & 130392 & 67097 & 59013 & 42087 \\
\hline 9 & 222059 & 46961 & 25991 & 32014 \\
\hline 10 & 55673 & 3484 & 5498 & 2469 \\
\hline 11 & 3066 & 1107 & 709 & 1645 \\
\hline 12 & 1535 & 450 & 172 & 871 \\
\hline
\end{tabular}

In contrast with the CG lightning amount of each year in Figure 4, it is easy to conclude that, in addition to complying with the distribution of "more in summer and less in winter", CG lightning also has the characteristic of "twin peaks" that is the spring (summer) peak and summer (autumn) peak, namely the lightning activities is enhanced in summer and autumn, in 2010, for example, when the flash frequency stayed low from January to April, significantly increasing in May, and come up to the peak in June, followed by slightly decrease in July and August, however in September the CG flash reached to another peak in September, and then quickly fell.

"Twin peaks" statistical results from 2010 to 2013 are shown in Table 5. Obviously, the peak of spring (summer) generally occurs in about May, while summer (autumn) peak in August, with an interval about 2 months. The significant characteristic of CG lightning distribution illustrates that, regardless of macroscopic meteorological conditions, atmospheric thermal circulation are almost consistent in the same area every year, which can help the power grid corporation for rational allocation of transport resources, to improve the efficiency of resource utilization and operational management level.
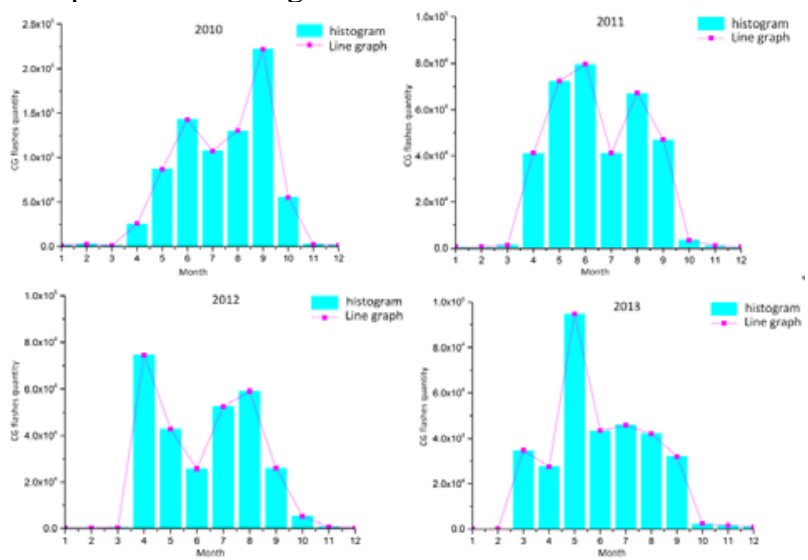

Figure 5. Monthly cg flashes quantity diagram from 2010 to 2013

TABLE V. “Double PeAK” Statistics From 2010 To 2013

\begin{tabular}{|l|c|c|c|c|}
\hline \multicolumn{1}{|c|}{ Year } & $\mathbf{2 0 1 0}$ & $\mathbf{2 0 1 1}$ & $\mathbf{2 0 1 2}$ & $\mathbf{2 0 1 3}$ \\
\hline $\begin{array}{l}\text { spring(summer) } \\
\text { peak month }\end{array}$ & 6 & 6 & 4 & 5 \\
\hline $\begin{array}{l}\text { summer(autumn) } \\
\text { peak month }\end{array}$ & 9 & 8 & 8 & 7 \\
\hline interval & 2 & 1 & 3 & 1 \\
\hline
\end{tabular}

\section{Distribution Per Hour}

In order to study the change characteristics of CG lightning quantity per hour of Hainan island, the number of CG lightning in 24 hours with ten minutes interval from 2010 to 2013 was statistical analyzed, as shown in Figure 6. Some characteristics can be found ${ }^{[14]}$.

- Daily CG flashes, presenting significant "Twin Peaks" feature, with "early peak" at 05:00 and "afternoon peak" at 17:00, and the latter is much larger than the former in quantity, accounting for at least $60 \%$.

- The total number of CG flashes in 2010 is far above the other years, for details see section 2.1.

- the minimum quantity per hour of CG flashes in Hainan island is roughly 10 thousand, comparing the maximum of 27 thousand.

- $\quad$ "Afternoon peak", spanning 13:00 and 19:00, rising fast between 14:00 - 16:00, and reaches the peak at about 17:00, then decrease quickly, slowed down at about 18: 00 .

TABLE VI. C C F Flashes StAtistics In AN Hour From 2010 To 2013

\begin{tabular}{|l|c|c|c|c|}
\hline \multicolumn{1}{|c|}{ Year } & $\mathbf{2 0 1 0}$ & $\mathbf{2 0 1 1}$ & $\mathbf{2 0 1 2}$ & $\mathbf{2 0 1 3}$ \\
\hline morning peak (h) & $4 \sim 8$ & $3 \sim 6$ & $4 \sim 7$ & $4 \sim 8$ \\
\hline noon peak (h) & $13 \sim 19$ & $14 \sim 19$ & $13 \sim 20$ & $13 \sim 20$ \\
\hline $\begin{array}{l}\text { Proportion of } \\
\text { noon peak(\%) }\end{array}$ & 72.8 & 67.1 & 70.6 & 65.6 \\
\hline
\end{tabular}




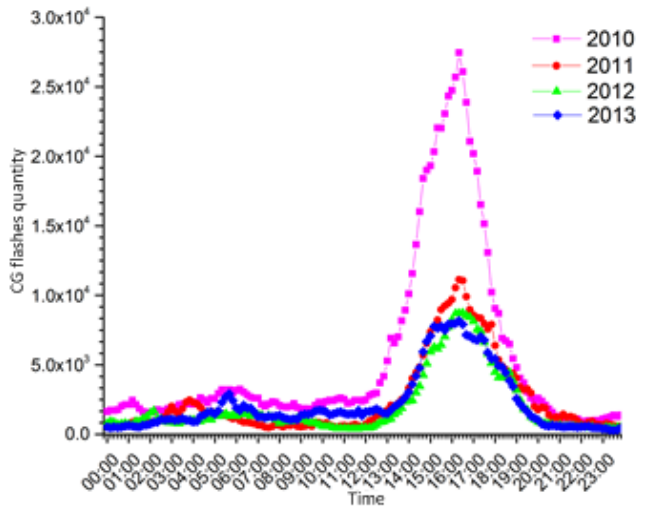

Figure 6. CG flashes quantity curve per hour of Hainan island from 2010 to 2013

\section{SPATIAL FEATURES}

Figure 7 is the spatial distribution of CG flashes density of Hainan island in $2010 \sim 2013$, it can be seen that the flash densities is quite large in most of Hainan island, which were respectively 2.2 flashes $/ \mathrm{km}^{2} /$ year, 1.0 flashes $/ \mathrm{km}^{2} /$ year, 0.81 flashes $/ \mathrm{km}^{2} /$ year, 0.92 flashes $/ \mathrm{km}^{2} /$ year, the average annual flash density was 1.2 flashes $/ \mathrm{km}^{2} /$ year.
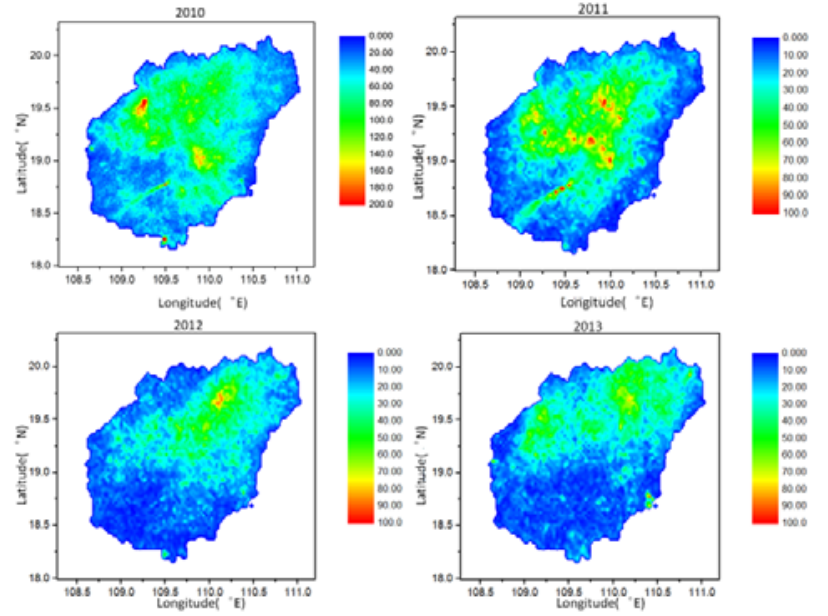

Figure 7. Flash density of Hainan island in 2010 2013

\section{CONCLUSION}

Based on the statistical analysis of LLSH data, CG flashes distribution characteristics and its causes of Hainan island were further studied from different time interval and space dimensions, the conclusion is as follows:

- There is a strong correlation between the lightning intensity of Hainan island and NINO3.4 index, therefore the flash quantity can be predicted by NINO3.4 index.

- Temporal distribution of Lightning on Hainan island has obvious "twin peaks" characteristics, the spring (summer) peak generally occurs in about May, while the summer(autumn) peak in August, with an interval of about 2 months;

- Daily CG lightning of Hainan island has obvious aggregation phenomenon, which also presents the "twin peaks" characteristics, respectively in 05:00 and 17:00, and the latter is more intensive.

- The flash density of Hainan island mainly appear in the mountainous areas in the northeast, and largely centered on windward area.

\section{ACKNOWLEDGMENT}

This work is in part supported by the National ScienceTechnology Support Plan in the domain of advanced energy technology. Hainan Power Grid Corporation provided support for this research through "Integrated Demonstration Project of Regional Smart Grid” no. 2013BAA01B03.

\section{REFERENCES}

[1] ChenJiahong, ZhangQin, FengWanxing, FangYuhe, "China Power Grid Lightning Location System and Lightning Monitoring Network”,High Voltage Technology, 2008, vol.34, pp. 425-431.

[2] Wang, Haohao, Luo Jianyu, Xu Taishan, Li Haifeng, Li Bijun, Zhu Huan, Xue Yusheng,"'Investigation and Analysis of Natural Disaster Prevention Technology Situation in China Power Grid “, Journal of the China Railway Society, 2006, vol.28 pp. 85-88.

[3] Gu Shanqiang, Chen Jiahong, Chen Weijiang, Feng Wanxing, Guo Juntian, Zeng Yu," Method for Lightning Flashover Warning of Overhead Transmission Lines”, High Voltage Technology, 2013, vol.39(3), pp. 423-429.

[4] Kenneth L. and Martin J. Murphy, “An Overview of Lightning Locating Systems : History, Techniques, and Data Uses, With an InDepth Look at the U. S. NLDN", IEEE Transactions on Electromagnetic Compatibility, 2009, vol.51, pp. 499-518.

[5] Guo Juntian, Gu ShanQiang, Feng Wanxing, “A Lightning Motion Prediction Technology Based on Spatial Clustering Method”, 2011 7th Asia-Pacific International Conference on Lightning. 2011, pp. 788-793.

[6] Carlos Alberto Vasconcellos, Cesar Beneti, Fábio Sato, Luciane Cristina Pinheiro, "Electrical Thunderstorm Nowcasting Using Lightning Data Mining”, 19th International Lightning Detection Conference, 2006, pp. 1-3.

[7] Chen Youlong, Guo Dongyan Li Fan, "Test and Analysis of Hainan Lightning Location System,” Journal of Meteorological Research and Application, 2010, vol.31, pp. 94-97.

[8] C. Mueller, T. Saxen, R.Roberts, J. Wilson, T. Betancourt, S. Dettling, N. Oien, and J. Yeencar, “Auto-Nowcast System", Weather and Forecasting, 2003, vol.18, pp. 545-561.

[9] Chen Mingxuan, Yu Xiaoding, Tan Xiaoguang, Wang Yingchun, "Development and Progress in Convective Weather Forecasting Technology ”, Journal of Applied Meteorological Science, 2005, vol.15, pp. 754-766.

[10] Sun Ling, Zhou Yunjun, Yang Jing, "Research Progress of Thunderstorm Prewarning and Forecasting”, Plateau and Mountain Meteorology Research, 2009, vol.29, pp. 75-80.

[11] Kishor Kumar Reddy C;Anisha P R;Narasimha Prasad L V, "Detection Of Thunderstorms Using Data Mining and Image Processing”, the Fifth International Conference on the Applications of Digital Information and Web Technologies (ICADIWT), 2014, vol.5, pp. 226-231.

[12] ULLI FINKE, "Space-Time Correlations of Lightning Distributions”, Monthly Weather Review, 1999, vol.127, pp. 1850-1861.

[13] Ileana Baran, "Featuring the thunderstorm activity using lightning data provided by the Romanian Lightning Detection and Location Network”, IEEE Bucharest Power Tech Conference, 2009, pp. 1-8. 
[14] C. Price • Y. Yair • A. Mugnai • K. Lagouvardos • M. C,et al, “ Using Lightning Data to Better Understand and Predict Flash Floods in the Mediterranean”, Surv Geophys, 2011, vol.32, pp. 733-751. 